\title{
Granulocytic sarcoma (chloroma) causing spinal cord compression
}

\author{
B.J.Frohna, D.J. Quint \\ Department of Radiology, University of Michigan Hospitals, Ann Arbor, Michigan, USA
}

Received: 23 June 1992/Received in revised form: 21 October 1992

\begin{abstract}
Granulocytic sarcoma (chloroma) is a rare solid tumor of myelogenous stem cells, usually appearing in patients with acute myelogenous leukemia and less commonly in patients with chronic myelogenous leukemia or myeloproliferative disorders. We present a spinal epidural granulocytic sarcoma causing thoracic spinal cord compression in a patient with chronic anemia secondary to myelofibrosis.
\end{abstract}

Key words: Chloroma - Myelofibrosis - Spine MRI

\section{Case report}

A 77-year-old man presented in October 1989 with chronic anemia, at which time bone marrow biopsy revealed myelofibrosis. He was treated with monthly blood transfusions, progressing to weekly transfusions in February 1991. In March 1991, he developed low back pain; there was no associated trauma, and the pain was worse when he was supine as opposed to standing. He had unsteadiness of gait, but motor and sensory examination was normal, as were bladder and bowel function. He was admitted for pain management in late April 1991. An EMG at that time showed peripheral neuropathy but no radiculopathy.

Plain radiographs of the spine were normal. MRI demonstrated a contrast enhancing, posterior epidural soft tissue mass extending from $\mathrm{T} 5$ to L2, displacing and compressing the spinal cord anteriorly (Fig.1). Differential diagnosis included extramedullary hematopoiesis (EMH), lymphoma, and leukemic mass. No biopsy was performed because of the patient's profound thrombocytopenia (platelet counts ranged between $15,000-30,000 / \mathrm{mm}^{3}$ despite transfusions). Radiation therapy was not offered because of potential marrow toxicity in the setting of profound pancytopenia. The patient became paraplegic nine days after the MRI, and expired 4 days later.

A limited autopsy demonstrated a tan, shiny, cylindrical, epidural mass, $0.9 \mathrm{~cm}$ in diameter posteriorly in the spinal canal. Microscopic examination revealed primarily immature cells of the granulocytic series. Bone marrow biopsy revealed granulocytic hyperplasia and a

Correspondence to: D.J. Quint, B1D530H, Neuroradiology, Department of Radiology, Box 30, University of Michigan Hospitals, 1500 East Medical Center Drive, Ann Arbor, Michigan 48109-0030, USA "left shift", consistent with blast transformation of an underlying myeloproliferative disorder. A final diagnosis of granulocytic sarcoma (chloroma) was made.

\section{Discussion}

Epidural granulocytic sarcoma (chloroma) was first described by Burns in 1811. He described a greenish-yellow tumor of the dura mater of uncertain etiology. King first coined the term "chloroma" in 1853 (from Greek chloros, green), and Dock described the association between chloroma and leukemia in 1893 . The characteristic color is due to elevated levels of the enzyme myeloperoxidase in tumor cells of myeloid origin; this enzyme is present in lesser amounts in normal myeloid cells [1]. However, the tumors are usually gray, white or tan-brown, as in the present case, owing to the oxidation of the enzyme upon exposure to air. The green color can be reproduced by treating the tumor with hydrogen peroxide or sodium metabisulfite. For this reason, the pathologic term granulocytic sarcoma is preferred; myeloblastoma has also been used [2]. The tumors are soft or hard [3].

Granulocytic sarcomas have been reported in 3.1$9.1 \%$ of patients with acute myelogenous leukemia (AML) $[1,4,5]$. Less commonly, they have been reported in chronic myelogenous leukemia, and more rarely, myeloproliferative disorders, including polycythemia vera, hypereosinophilia, and myeloid metaplasia. In the latter case, their occurrence is prognostically ominous, often associated with conversion to AML, or blast crisis [1]. They usually occur concurrently with clinical evidence of leukemia, although they may arise while the patient is in clinical remission, and may antedate the diagnosis of leukemia by up to two years. They are more frequent in children, with $60 \%$ of patients under 15 years of age [6]. Their incidence is rising, secondary to prolonged survival times in patients with myelogenous leukemias.

Bone (including cranium, sacrum, sternum, ribs, and spine) is the most common site, followed by skin, soft tissues, lymph nodes, and dura mater [7-9] although 

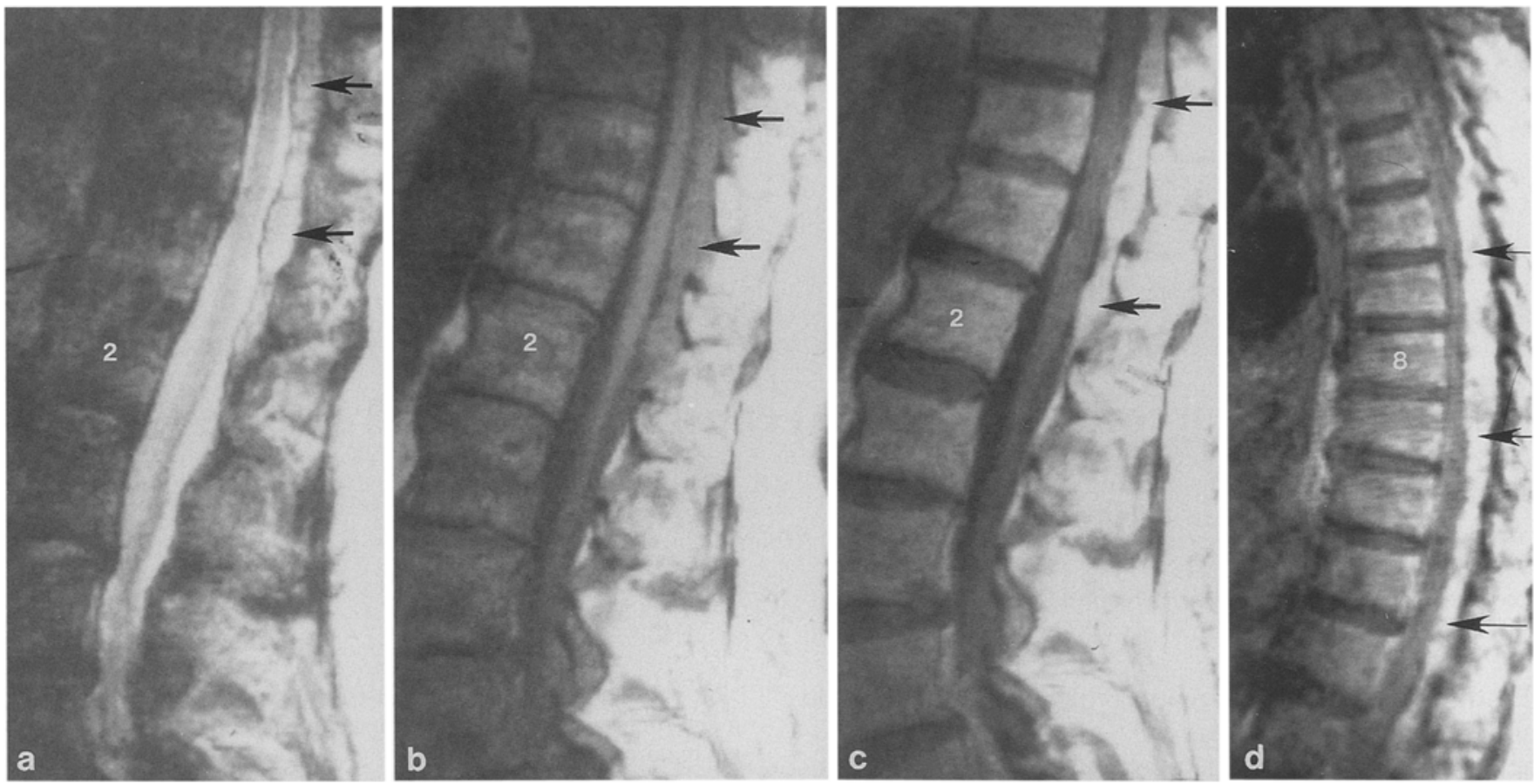

Fig. 1 a-d. Sagittal MRI demonstrates a posterior extradural mass extending from $\mathrm{T} 5$ to L2 (arrows), hyperintense relative to the spinal cord on a T2-weighted image (a), isointense with cord on a T1weighted image (b) and demonstrates homogeneous contrast enhancement $(\mathbf{c}, \mathbf{d})$. The lesion appears to compress the lower thoracic spinal cord. Autopsy revealed granulocytic sarcoma (chloroma). 2, L2 vertebral body 8 , T 8 vertebral body

involvement of every organ system has been reported $[3,10]$. Involvement of bone is typically subperiosteal. It has been postulated that leukemic cells enter the periosteum by migrating from the marrow through Haversian canals, and thence invade the dura mater [11]. Direct involvement of the CNS is rare, but has been reported [11]. It has been suggested that leukemic cells infiltrate the CNS via perivenous adventitial tissue connecting the dura mater and subarachnoid space. The brain is infiltrated by direct spread from the arachnoid mater [12].

Patients with chloromas involving any tissue present with local pain ( $78 \%$ ), tumor nodules $(65 \%)$, and motor or sensory disturbances $(52 \%)$, in addition to the usual signs and symptoms of leukemia [3]. Spinal canal involvement by granulocytic sarcoma has been reported to cause back and leg pain, urinary incontinence, and acute paraplegia, often with fulminant progression $[4,5]$. Adequate control of the tumor can be obtained with radiation and/or chemotherapy [9]; surgical intervention is rarely necessary, except in cases of acute cord compression [2].

The CT and MRI appearances of spinal epidural chloromas have not been previously described other than in a patient with spinal cord compression secondary to epidu ral chloroma who became symptomatic after a lumbar puncture [13], for whom only unenhanced T1-weighted spinal images were illustrated.
Intracranial granulocytic sarcomas have been described on CT as of intermediate to high attenuation (60$80 \mathrm{HU})$ and typically demonstrate uniform contrast enhancement $[6,14,15]$; this CT pattern is, of course, nonspecific. On MRI intracranial lesions have been described as isointense with white matter on both T1- and T2weighted images [7], or isointense with gray matter on T1weighted images and isointense with white matter on T2weighted images [6]. Angiographically, these tumors demonstrate mild to moderate hypervascularity, usually arising from a meningeal artery.

The differential diagnosis of a predominantly posterior, extradural spinal canal mass extending for several levels in the thoracic region includes hematoma, abscess, meningioma, granulocytic sarcoma, metastatic disease, lipomatosis, lymphoma, and EMH. Many of these lesions can be differentiated on the history or the results of imaging. However, EMH, a rare entity, may radiographically and clinically mimic chloroma, and has been called pseudochloroma [16]. Furthermore, EMH occurs in many of the groups of patient prone to chloroma, including those with leukemia and myeloproliferative disorders, and may mimic intraspinal chloroma on CT and MRI [16]. Spinal EMH is most common in the thoracic region, and has been reported to cause spinal cord compression. EMH masses can be treated with radiation therapy and/or surgery [16-21].

It is important to differentiate EMH (pseudochloroma) from granulocytic sarcoma (chloroma) for two reasons. First, chloroma carries an ominous prognostic significance, usually indicating recurrence of leukemia, or conversion of a non-leukemic condition to leukemia. Second, EMH is treated with radiation therapy, with doses of 935 Gy in $10-15$ fractions $[17,20,21]$, while chloromas have been treated with radiation doses to $30 \mathrm{~Gy}$ initially, followed by systemic chemotherapy $[4-6,9,11,15]$. Since these lesions can appear identical on CT and MRI, biopsy 
may be the only way to separate them. Despite the risks of bleeding in patients with leukemia and myeloproliferative disorders due to thrombocytopenia, biopsy should be strongly considered when the diagnosis is in doubt.

\section{References}

1. Neiman RS, Barcos M, Berard C, et al (1981) Granulocytic sarcoma: a clinicopathologic study of 61 biopsied cases. Cancer 48 : 1426-1437

2. Stork JT, Cigtay OS, Schellinger D, Jacobsen RJ (1984) Recurrent chloromas in acute myelogenous leukemia. AJR 142:777-778

3. Liu PI, Ishimaru T, McGregor DH, Okada H, Steer A (1973) Autopsy study of granulocytic sarcoma (chloroma) in patients with myelogenous leukemia, Hiroshima-Nagasaki 1949-1969. Cancer 31: 948-955

4. Kellie SJ, Waters KD (1984) Extradural chloroma with spinal compression - an unusual presentation of acute myelogenous leukaemia. Aust NZ J Med 14: 160-162

5. Sowers JJ, Moody DM, Naidich TP, Ball MR, Laster DW, Leeds NE (1979) Radiographic features of granulocytic sarcoma (chloroma). J Comput Assist Tomogr 3: 226-233

6. Kao SCS, Yuh WTC, Sato Y, Barloon TJ (1987) Intracranial granulocytic sarcoma (chloroma): MR findings. J Comput Assist Tomogr 11: 938-941

7. Leonard KJ, Mamourian AC (1989) MR appearance of intracranial chloromas. AJNR 10; S67-68

8. Cohen R, Segall HD, Nelson MD, Zee CS, Ahmadi J (1988) Bilateral retroorbital chloromas in a 16-month-old child: CT features. J Comput Assist Tomogr 12:895-896

9. Dunnick NR, Heaston DK (1982) Computed tomography of extracranial chloroma. J Comput Assist Tomogr 6: 83-85

10. Nickels J, Koivuniemi A, Heiskanen O (1979) Granulocytic sarcoma (chloroma) of the cerebellum and meninges. Acta Neurochir 46:297-301
11. Barnett MJ, Zussman WV (1986) Granulocytic sarcoma of the brain: a case report and review of the literature. Radiology 160: 223-235

12. Wang AM, Lin JCT, Power TC, Haykal HA, Zamani AA (1987) Chloroma of cerebellum, tentorium, and occipital bone in acute myelogenous leukemia. Neuroradiology 29:590

13. Wong MC, Krol G, Rosenblum MK (1992) Occult epidural chloroma complicated by acute paraplegia following lumbar puncture. Ann Neurol 31: 110-112

14. Woo E, Yue CP, Mann KS, Ngan H (1986) Intracerebral chloromas: unusual computed tomography appearance of leukemic infiltration. J Computed Tomogr 10:365-367

15. Pomeranz SJ, Hawkins HH, Towbin R, Lisberg WN, Clark RA (1985) Granulocytic sarcoma (chloroma): CT manifestations. Radiology 155: 167-170

16. Barton JC, Conrad ME, Poon M (1979) Pseudochloroma: extramedullary hematopoietic nodules in chronic myelogenous leukemia. Ann Intern Med 91: 735-738

17. Jackson DV, Randall ME, Richards F (1988) Spinal cord compression due to extramedullary hematopoiesis in thalassemia: long-term follow-up after radiotherapy. Surg Neurol 29: 389392

18. Mann KS, Yue CP, Chan KH, Ma LT, Ngan H (1987) Paraplegia due to extramedullary hematopoiesis in thalassemia. J Neurosurg 66: 938-940

19. Singounas EG, Sakas DE, Hadley DM, et al (1991) Paraplegia in a pregnant thalassemic woman due to extramedullary hematopoiesis: successful management with transfusions. Surg Neurol 36: $210-215$

20. Hassoun H, Lawn-Tsao L, Langevin ER, Lahti ES, Palek J (1991) Spinal cord compression secondary to extramedullary hematopoiesis: a noninvasive management based on MRI. Am J Hematol 37: 201-203

21. Kaufmann T, Coleman M, Giardina P, Nisce LZ (1991) The role of radiation therapy in the management of hematopoietic neurologic complications in thalassemia. Acta Hematol 85: 156159 